\title{
Determinants of Small Business EDI Adoption: An Empirical Investigation
}

\author{
Patrick Y. K. Chau \\ School of Business \\ University of Hong Kong \\ Kai Lung Hui \\ Department of Information Systems \\ School of Computing \\ National University of Singapore
}

\begin{abstract}
Given the importance of widespread adoption for the success of electronic data interchange (EDI) and the "much-slower-than-anticipated" growth of EDI adoption in small businesses, in this study we aimed to identify the key determinants of small business EDI adoption. Based on prior research on IT/EDI adoption in large/small organizations, a model that incorporates 7 factors that are hypothesized to have influence on the EDI adoption decision was developed and empirically tested against data collected from 627 small businesses, with 38\% of them having already adopted the technology. The findings suggest that in the eyes of small businesses, EDI still is not considered as something that enables a business to gain major strategic benefits or competitive advantages. Although perceived costs are found to be major impediments to adoption, small businesses tend to have an "unbalanced" treatment between direct and indirect benefits, focusing more on those that are immediate and direct rather than on long-term, indirect benefits. Furthermore, prior EDI experience and perceived level of support from the vendor are also important determinants of EDI adoption in small businesses. Implications to Internet-based EDI systems are also discussed.
\end{abstract}

small business, electronic data interchange, IT adoption, interorganizational information systems

\section{INTRODUCTION}

Like other interorganizational information systems (IS), electronic data interchange (EDI) has been discussed in the literature as a technology that can provide strategic advantage to its adopters [1]. Given its well-publicized benefits, the growth of EDI adoption in small businesses, however, has been slower than anticipated and is

\footnotetext{
This work was substantially supported by a grant from the Research Grants Council of the Hong Kong Special Administrative Region, China (Project No. HKUST583/96H).

Correspondence and requests for reprints should be sent to Patrick Y. K. Chau, School of Business, University of Hong Kong, Pokfulam, Hong Kong. E-mail: Pchau@business.hku.hk
} 
much slower than that in large organizations [2]. Despite its ability to replace inefficient and costly paper-based processes with computer-based communication, it appears that small firms are still reluctant to adopt this technology.

Using Swanson's [3] taxonomy of IS innovations, EDI can be categorized as a Type III innovation. Swanson asserted that compared to small organizations, large organizations process input in sufficient volume, interact more frequently with the external environment, and have a greater variety of specialized tasks, thus justifying more frequent adoption of Type III innovations. Small businesses, on the other hand, are often characterized as firms with low levels of IT sophistication and resource availability, weak market position, and underutilization and lack of integration of IT. These constraints may cause small businesses to refrain from adoption of Type III innovations such as EDI. The problem is more of a concern because small businesses are the backbone of the economy of many countries. For example, in the United States, small businesses create two of every three new jobs, produce $39 \%$ of the gross national product, and invent more than half of the United States's technological innovations [4].

In light of the importance of a high penetration level for the success of EDI, it is therefore important to understand what major factors influence the adoption of EDI in the small business context. We address this issue in this study. From a theoretical perspective, we also address the lack of general theories and research on the adoption of IT for competitive purposes in small firms.

The organization of the article is as follows. In the next section, we discuss a theoretical framework for small business EDI adoption, which is formulated by reviewing past conceptual and empirical research on IT and/or EDI adoption. Next, we present a research model derived from the framework. The research method, data analysis, and results then follow. We conclude the article with discussions of the research findings and the contributions of the study to research and managerial practice.

\section{LITERATURE REVIEW}

Although a large number of studies on either EDI adoption in large organizations or IT adoption in small businesses can be found in literature, little research has been done specifically on EDI adoption in small businesses. Three major areas of research were thus reviewed to provide the necessary theoretical foundations for this study. The three areas are adoption of IT innovations, EDI adoption, and small business EDI adoption.

\subsection{Adoption of IT Innovations}

Studies on adoption of IT innovations have been well documented in the literature. Many of these studies are based on Rogers's [5] diffusion of innovations (DOI) theory. Recent works along this line include Moore and Benbasat [6], Rai and Howard [7], and Premkumar and Potter [8]. The DOI theory posits that diffusion of an innovation depends on five general attributes including relative advantage, compatibil- 
ity, complexity, observability, and trialability. Tornatzky and Klein [9] conducted a meta-analysis of findings from studies on innovation characteristics and innovation adoption and concluded that compatibility, complexity, and relative advantage are variables consistently deemed important in the adoption issue. Nevertheless, researchers on complex organizational technology and interorganizational IS have criticized the deficiencies of the DOI theory in explaining the adoption behavior. For example, Brancheau and Wetherbe [10] noted that "it was clear that innovation diffusion theory did not provide a complete explanation for technology diffusion in organizations" (p. 138). In a review of IT innovation studies, Fichman [11] argued that classical diffusion variables by themselves are unlikely to be strong predictors of adoption and diffusion for complex organizational technology, suggesting that additional factors, either as independent or control variables, should be added. In studies of adoption of interorganizational systems, Prescott and Conger [12] concluded that "DOI factors are not as appropriate for inter-organizational information technologies as they are for the others. ... There is already substantial indication that traditional DOI findings must be modified when applied to inter-organizational systems" (p. 32).

The preceding review indicates that using the DOI theory alone may not be sufficient to help understand the adoption behavior of a complex organizational technology and/or interorganizational IS such as EDI.

\subsection{EDI Adoption Studies}

EDI has been discussed in the literature as a technology that can provide both operational and strategic advantages to its adopters. Because of that, quite a few studies have been conducted to examine factors affecting the adoption or the success of the adoption of EDI. For example, O'Callaghan et al. [13] performed an extensive survey study on EDI adoption in marketing channels. With a sample size of 1100 firms, their results show that among the five innovative attributes in Rogers's [5] DOI framework, relative advantage and compatibility have significant relations with EDI adoption. In another study, Premkumar et al. [14] examined Rogers's five innovative attributes in the context of EDI adoption. With 200 organizations in various industry groups surveyed, the study concluded that relative advantage, technical compatibility, and cost are significant factors in making the EDI adoption decision.

Several studies have focused on the influence of interorganizational factors on EDI adoption. For instance, Bouchard [1] examined the influence of trading partners in EDI adoption decisions by retail suppliers. Based on responses from 175 suppliers, the influence of trading suppliers was found to be a significant factor in the adoption decision. Neo et al. [15], using TradeNet in Singapore as the case, examined the significance of peer influence and coercive influence-in addition to relative advantage and trialability - on the EDI adoption decision. They found that both peer influence and trialability were significant factors in the adoption decision. In another study, Premkumar and Ramamurthy [16] examined the role of several interorganizational factors in the decision mode for EDI adoption. The results suggest that exercised power and competitive pressure are significant to discriminate between adoption decision modes. 


\section{CHAU AND HUI}

Factors related to the internal environment of an organization and the EDI adoption decision have also been examined in several studies. For example, Drury and Farhoomand [17] used an administrative innovation approach to examine EDI adoption in organizations. Based on responses from 379 respondents, lack of knowledge of and training in EDI were found to be major impediments to adoption. McGowan and Madey [18] investigated the impact of the organization's structural characteristics and organizational learning factors on EDI adoption and use. The level of EDI knowledge and technical expertise were found to have positive influence on EDI adoption and use.

The preceding review suggests that previous EDI adoption studies, by and large, have focused on factors in three main areas: the technology itself, the external environment, and the organizational context. However, as commented by Raymond and Bergeron [19], "although they (previous EDI studies) provide fruitful results, these studies are not easily generalizable to small and medium-sized enterprises" (p. 162). Thong et al. [20] also asserted that

Organizational theories or practices that are applicable to large organizations may not fit in the SME context.... There is a need to take off the big-organization glasses and to look at SMEs separately, not in the relational view commonly used. (p. 249)

\subsection{Small Business EDI Adoption Studies}

There has been little research specifically studying small business EDI adoption. Iacovou et al. [21] and Raymond and Bergeron [19] are two notable EDI adoption studies that focused on small businesses. In Iacovou et al. [21], three factors-perceived benefits of EDI, organizational readiness, and external pressure-were hypothesized as the main sources that could influence the EDI adoption behavior of small firms. The proposed research model was examined through in-depth case studies of seven small firms. Their findings suggest that external pressure plays the most influential role in the EDI adoption behavior of small businesses. The relation between perceived benefits of EDI adoption is moderate, whereas the overall readiness of small firms is not high enough to make any influence on the adoption decision. The study concluded that their case-based investigation provided preliminary findings on the adoption of EDI on small firms, and future large-scale, empirical investigations of the subject might use the suggested model as the theoretical basis.

The study by Raymond and Bergeron [19] investigated a different aspect of EDI adoption in small businesses. Their research aimed to identify factors that help small and medium enterprises obtain advantages from EDI. The participants in the study were EDI users. The research model was adapted from another model that was used to investigate the advantages of EDI in general, in which the sample consisted of large organizations for the most part [22]. Six variables, including organizational support, implementation process, control procedures, internal integration, external integration, and imposition level, were included in the model and were hypothesized to have influence on obtaining EDI advantages in small businesses. Based on a field study conducted in 39 small firms, the findings suggest that organizational support, implementation process, and to a lesser extent, control 
procedures are all significant in terms of supporting the firm in obtaining the EDI advantages. The relationship between EDI advantages and the other three variables were not found to be significant. A weakness of the study, however, is its small sample size, thus limiting its data analysis to rigorous statistical tests.

The findings of the previously mentioned two studies indicate that the EDI adoption behavior in small businesses may be influenced by not just the technology itself (i.e., perceived benefits of EDI) but also the organizational environment, such as organizational support and the implementation process, and the external environment, such as pressure from competitors and/or partners in particular. This observation, to a great extent, matches with findings of many adoption studies of organizational technology in the large-organization context as described in the literature review section previously. In other words, the same groups of factors that affect EDI adoption decisions in large organizations may also have influence on the EDI adoption decisions in small-business context, even though the magnitude and effect may not be the same. Therefore, a research model on the EDI adoption in small businesses might be constructed around these three contexts, namely: (a) the technological context, (b) the external environmental context, and (c) the organizational context.

\section{RESEARCH MODEL}

Figure 1 depicts the research model. It ties together seven factors representing the three major contexts of EDI adoption in small businesses discussed previously.

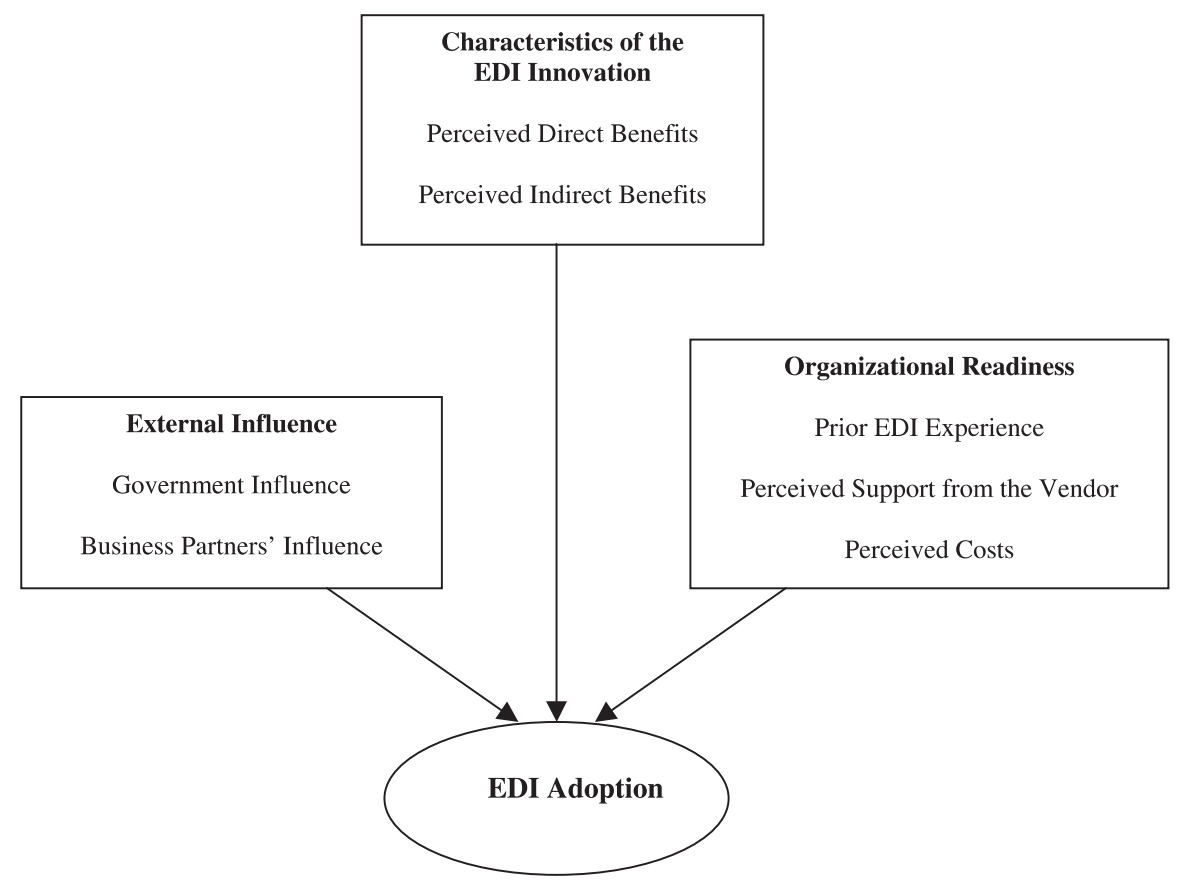

Figure 1. A model for small business EDI (electronic data interchange) adoption. 


\section{CHAU AND HUI}

The technological context looks into the characteristics of EDI innovation that reflect the unique attributes of EDI to small businesses. The main focus is on how technology characteristics themselves can influence the adoption process. Different organizations may face very different innovation opportunities. Whether these innovation opportunities can be exploited depends on the degree of the match between the characteristics of the innovation and the practices currently adopted by the organization. The degree of the "match" depends on the potential benefits or relative advantage of adopting the technology. Therefore, the relative advantage of the adoption is modeled as an important factor in this technological context. Iacovou et al. [21] also included this factor as one of the three important factors in their model. The emphasis on context implies that the operationalization of relative advantage must be defined in light of the innovation characteristics.

The external environmental context examines the "arena" in which an organization conducts its business. Because EDI is an interorganizational system, influence by other stakeholders on the adoption decision is important [16]. Depending on the kind of the technological innovation, these factors may present either constraints or opportunities for the organization to perform adoption activities. In our study, these external parties include the government and business partners. ${ }^{1}$

The organizational context looks at the structure and processes of an organization that constrain or facilitate the adoption and implementation of innovations. In the case of technology adoption, the organizational context can be viewed as both the technological and the financial status in a small business that presents constraints and opportunities for the adoption. The technological constraints may include EDI experience and support from external parties. The financial constraints mainly deal with the perceived costs to be incurred in the adoption. Iacovou et al. [21] also examined these two types of constraints and grouped them as two major factors affecting the level of "organizational readiness" to the adoption. In the following subsections, we describe each of these contexts in detail.

\subsection{Technological Context}

Many studies have been conducted to discover the relationship between the characteristics of an innovation and the innovation process [23]. An important group of characteristics affecting the innovation process are those related to the cost-benefit trade-off of adopting a particular innovation. For example, based on Rogers's [5] classical diffusion framework, Tornatzky and Klein [9] performed a meta-analysis that concluded that relative advantage, compatibility, and complexity are the three factors that have consistent associations with innovation behaviors. Furthermore, relative advantage is the only variable that has been consistently identified as a critical adoption factor and as the most important factor for IT growth in small firms [24]. Premkumar et al. [14] also found that the relative advantage of EDI is one of the major predictors of the initial use in the first application.

In the context of EDI, the relative advantage of the adoption can be regarded as the level of recognition that adopting the technology can provide to the organization

\footnotetext{
${ }^{1}$ Influence from competitors is not included in our study, as the EDI service investigated is of a business-to-government, not business-to-business, type. Peer pressure from competitors for a small business to use EDI is believed to be not important in this context.
} 
[21]. Pfeiffer [25] distinguished direct from indirect benefits. Direct benefits are those mostly for operational savings and are related to the internal efficiency of the organization. Examples include reduce transaction errors, improve data accuracy, reduce transaction costs, improve information quality, and speed up application process. Indirect benefits are those mostly for tactical and competitive advantages and are related to the impact of EDI on the business process and relationships [21]. Examples include improve competitive advantage, improve customer services, and improve relationship with business partners. Even though quantifying such benefits, indirect benefits in particular, is generally recognized as difficult, a strong, even if vague, perception of these benefits is believed to favor the decision to adopt EDI. This is especially true in the context of small business, as many prior studies have found empirical evidence on the importance of this group of factors on IT adoption [19]. The preceding arguments lead to the following two hypotheses:

H1: Higher levels of perceived direct benefits of adopting EDI will positively affect the likelihood of EDI adoption by small businesses.

H2: Higher levels of perceived indirect benefits of adopting EDI will positively affect the likelihood of EDI adoption by small businesses.

\subsection{External Environment Context}

EDI is an interorganizational system in which other stakeholders in the network play an important role. The influence can be from the government or from the industry (including industrial leaders, business partners, or competitors) and in a positive manner (e.g., promotion and/or recommendation of the technology) or in a negative manner (e.g., pressure and/or imposition from business partners and/or the government).

Unlike other IS innovations, EDI can be business-to-business or business-to-government. In the latter case, the government usually plays an important role in the promotion or enforcement of using the system. One example is the TradeNet used in Singapore. The EDI system is a government initiative and it is mandatory for traders to submit structured electronic trade permit applications to the Trade Development Board in Singapore through the system. Organizations therefore adopt it due to the government influence and its regulations [15]. Another example is ValuNet used in Hong Kong for trading companies to lodge trade declarations for their exports. Both the government and Tradelink, the service provider of ValuNet, have been actively promoting the system to local organizations.

Industry influence is important in the small business context, as compared to large organizations small firms tend to have fewer resources to build up their internal knowledge base on current technological trends and developments. They tend to rely on other business partners to assist in their decision making. As stated by Hart and Saunders [26], business partners' influence is most likely to be a significant factor in the EDI adoption decision by less powerful partners. ${ }^{2}$

Based on the preceding arguments, two hypotheses are formulated as follows:

\footnotetext{
${ }^{2}$ The influence can also come from competitors. Recent studies include Premkumar and Ramamurthy [16] and Iacovou et al. [21]. However, as explained in footnote 1, our study does not include this competitor factor.
} 
H3: Higher levels of government influence on adopting EDI will positively affect the likelihood of EDI adoption by small businesses.

H4: Higher levels of business partner influence on adopting EDI will positively affect the likelihood of EDI adoption by small businesses.

\subsection{Organizational Context}

As in Iacovou et al. [21], an important factor in the organizational context is the level of organizational readiness with respect to EDI adoption. This readiness covers two aspects: technological and financial.

Depending on the existing IT experience and practices adopted, some organizations may require more effort than others to introduce an IT innovation [27]. In the context of EDI adoption by small businesses, two factors related to this technological constraint are proposed: (a) prior EDI experience by the firm and (b) perceived or anticipated support from external parties such as EDI service providers.

As emphasized in many research studies in small businesses, a small business is not simply a scale model of a large business. Unlike their counterparts, small businesses are characterized by lack of both IT experience and sufficient internal IS expertise [20]. Kwon and Zmud [23] asserted that sufficient organizational resources, in terms of both user experience and technical skills, are important for successful IS implementation. Cragg and King [24] also found that one key factor that inhibits small-firm computing is the lack of technical knowledge of the IT to be adopted. Therefore, a sufficient level of IT experience (or EDI experience in the context of this study) is expected so that the small business may feel "ready" to adopt the EDI technology.

Besides the lack of experience of the corresponding technology, small businesses generally also face difficulties in recruiting and retaining internal IS experts due to scarce financial resources and limited career advancement prospects. Instead of relying on internal IT support, they count on external assistance. For instance, prior studies on IT adoption in small businesses have found little support for the influence of both internal support and internal training on IT adoption [28], whereas effective external IS expertise is found to be more important in the small business context [20]. In addition, small businesses that rely on support from vendors tend to have more effective IS than those that rely on support from external consultants [29].

The preceding arguments lead to the following two hypotheses:

H5: Higher levels of prior EDI experience will positively affect the likelihood of EDI adoption by small businesses.

H6: Higher levels of perceived external support from vendors will positively affect the likelihood of EDI adoption by small businesses.

Another aspect of the organizational readiness is the perceived costs to be incurred in adopting the technology. Perceived costs may come from two main sources: financial investment and administrative costs.

Financial investment deals with the setup costs, operating costs, and training costs related to the adoption. Prior studies on IT adoption in small businesses have 
identified lack of financial resources as an important impediment to IT adoption. Iacovou et al. [21] included financial readiness as an important factor for EDI adoption in small businesses. In their study, financial readiness referred to "financial resources available for EDI to pay for installation costs, implementation of any subsequent enhancements, and on-going expenses during usage ([21], p. 469). This seems to assume that the organization itself can accurately estimate the amount of investment to be incurred. As evidenced in other IT adoption studies, this may not always be the case. For instance, in Drury and Farhoomand's [17] study on innovation adoption of EDI, many nonadopters were found to lack accurate information regarding the costs of EDI. In another more recent study, Hoogeweegen et al. [30] proposed to use activity-based costing with simulation to quantify the costs and benefits of adopting EDI because many companies do not know how to assess the costs and benefits of investing in EDI. Moreover, a firm might still find it difficult to adopt the technology despite the fact that the resources needed are available. In other words, the perception of difficulty may be more important than what resources the firm available.

The other source of costs relates to the potential administrative and implementation costs incurred in the adoption process. EDI, categorized as a Type III innovation in Swanson's [3] typology of IS innovations, impacts not only the technical core of the organization but also the administrative core of the host organization business. The potentially high cost, in terms of getting the EDI system in place and in function, may reduce the incentive to adopt. In MacGregor et al.'s [2] study on adoption of EDI by small business, over $43 \%$ of the respondents indicated that additional work procedures were needed to make their EDI system fit their normal day-to-day operations. The aforementioned viewpoints lead to the following hypothesis:

H7: Higher levels of perceived costs on adopting EDI will negatively affect the likelihood of EDI adoption by small businesses.

\section{METHOD}

\subsection{Research Strategy}

Both case-based and survey-based approaches have been used to explore issues of EDI adoption in both large- and small-business contexts. Although the case study method can provide richer descriptions of the issue or phenomenon being investigated, surveys can "provide a basis for generalizing, allow for replicability, and permit some degree of statistical power" ([1], p. 367]. The survey method was chosen for this study so as to allow the study to be easily replicated and thus the findings to be reconfirmed or disconfirmed.

Because organizations but not individuals adopt EDI, the unit of analysis for the study was therefore at the organizational level. Participants for this study were required to be senior informed respondents within the organization. With the assistance of the organization that sponsored this research study, the names of either the owners or the top managers of the targeted organizations were obtained. As our targets were small businesses, the owner and the top manager were always the 
same person. A letter stating the purpose of the study and the strict confidence of the data was sent along with the survey package.

The EDI product or service being investigated in the study is called ValuNet. It is an EDI software run on a personal computer to allow a trading company in Hong Kong to lodge trade declarations for import and export via this electronic means. Import and export declarations are mandatory for every consignment shipped in or out of the territory. With ValuNet, companies can lodge their declarations directly with the government by their own computers and pay the appropriate charges electronically. The service is provided by a quasi-government company called Tradelink, which has been granted a 7-year franchise to offer the service. ${ }^{3}$

\subsection{Operationalization of Factors}

As discussed previously, only a few studies have been conducted in the context of small-business EDI adoption and most of them have used a case-study approach. Therefore, to operationalize the constructs in the model, direct use of instruments in previous studies is not always possible. Over half of the items used in the study were therefore specifically developed for this study based on literature in not just research journals but also the trade press and pamphlets published by vendors of EDI products. The Appendix lists the items used in the study. To make the comparison between adopters and nonadopters meaningful, adopters were asked to express their opinion on the items with respect to the time at which they decided to adopt the technology. ${ }^{4}$ Operationalization of the factors is discussed following.

Both perceived direct benefits and perceived indirect benefits were operationalized by items adapted from Iacovou et al. [21] and Arunachalam [31]. Respondents were asked to give their level of agreement or disagreement with the potential direct or indirect benefits of adopting the EDI product on a scale ranging from 1 (strongly disagree) to 7 (strongly agree). Six items were used for measuring perceived direct benefits and five items were for perceived indirect benefits.

Government influence was operationalized with three items that measured the degree of influence of the promotion activities and mandatory measures carried out by the government on the adoption decision as perceived by the respondents. Respondents were asked to describe the degree of influence on a 7-point Likert-type scale ranging from 1 (no influence at all) to 7 (strong influence).

The business partners influence factor included four items. Respondents were asked to rate the degree of influence of their business partners on the EDI adoption decision. A 7-point Likert-type scale was used ranging from 1 (no influence at all) to 7 (strong influence).

Prior EDI experience was operationalized with three items that measured the experience/knowledge of the staff in the small businesses in using EDI software packages prior to the adoption. Respondents were asked to evaluate the degree of experience/knowledge on a 7-point scale ranging from 1 (very poor) to 7 (very good).

\footnotetext{
${ }^{3}$ More details about ValuNet and Tradelink can be found at their Web site: http://www. tradelink.com.hk

${ }^{4}$ It was understood that doing so might lead to a recall bias, which is discussed in the Limitations section of this article.
} 
Perceived support from the vendor was measured by three items that measured the perceived level of support provided by the EDI service provider in the areas of technical support, customer hotlines, and training. Respondents were asked to opine on the perceived level of support using a 7-point Likert-type scale ranging from 1 (very bad) to 7 (very good).

Perceived costs were measured by six items based on either prior studies $[17,31]$ or articles in various IT magazines. These items cover costs related to time, training, setup, and hardware and software involved. A 7-point Likert-type scale was used ranging from 1 (strongly disagree) to 7 (strongly agree).

The dependent variable, EDI adoption, was determined by a binary measure: adopters or nonadopters. Organizations were classified as adopters if they met the following two criteria: (a) already a subscriber of the EDI product being studied and (b) had lodged at least one trade declaration using ValuNet in the past 3 mo. Instead of asking the respondents to report their transactions, the list of the adopters was obtained from the EDI service provider.

\subsection{Participants}

Consistent with Igbaria et al. [28] and many other studies of small firm computing, small businesses in this study were defined as firms with not more than 100 employees. Participants were drawn from a list of current or potential customers of the EDI service being studied that was provided by the EDI service provider. The list contained 3000 names of organizations: 1000 current customers (i.e., adopters) and 2000 potential customers (i.e., nonadopters). The sample of nonadopters was randomly drawn from the master potential customer list maintained by the EDI service provider. The sample of adopters was obtained by randomly drawing those current customers who had subscribed to the service less than 1 year. ${ }^{5}$ Surveys were sent to all 3000 organizations between October and December 1998. A total of 659 questionnaires were returned, representing an overall response rate of $22 \%$. Of these 659 respondents, 32 had more than 100 employees and thus were excluded from the subsequent analysis. Therefore, our sample includes 627 small businesses in the manufacturing and trading industries with average annual sales around 1 million U.S. dollars. Two hundred and forty-one of them are adopters, whereas 386 are nonadopters. Statistical tests were conducted to examine the profile of the two groups of respondents. No significant differences were found in terms of number of employees, annual turnover, and industry coverage.

\subsection{Test of Factors}

The factors proposed in the model were tested for reliability, convergent validity, and discriminant validity. The reliability of the factors was assessed using Cronbach's alpha. As shown in Table 1, except for the government influence factor, all factors have an alpha value above .80. The alpha value for the government influence factor is .73, which is slightly lower than the others although still above the

${ }^{5}$ Doing so could help minimize the recall bias. 
Table 1

Reliability of Factors

\begin{tabular}{lccc}
\hline Factor & $M$ & $S D$ & Cronbach's $\alpha^{\prime}$ \\
\hline Perceived direct benefits $^{\mathrm{a}}$ & 4.88 & 1.43 & 0.8890 \\
Perceived indirect benefits $^{\mathrm{b}}$ & 4.13 & 1.46 & 0.9142 \\
Government influence $^{\mathrm{c}}$ & 4.81 & 1.85 & 0.7259 \\
Business partners influence $^{\mathrm{d}}$ & 3.18 & 1.71 & 0.9678 \\
Prior EDI experience $^{\mathrm{c}}$ & 3.08 & 1.55 & 0.8460 \\
Perceived support from the vendor $^{\mathrm{c}}$ & 4.53 & 1.47 & 0.8938 \\
Perceived costs $^{\mathrm{a}}$ & 4.31 & 1.67 & 0.8834 \\
\hline
\end{tabular}

Note. EDI = electronic data interchange.

${ }^{a} 6$ items. ${ }^{b} 5$ items. ${ }^{c} 3$ items. ${ }^{d} 4$ items.

minimum threshold as suggested by Nunnally [32]. Therefore, all seven factors are considered to exhibit sufficient reliability.

Factor analysis was used to test convergent validity and discriminant validity of the measurements. A principal component analysis with VARIMAX rotation and specifying a seven-factor solution was performed. Convergent validity is demonstrated if items load highly on their associated factors. Table 2 shows the results of the factor analysis. Without exception, all items load highly (loading above or at least at .50) on their associated factors, confirming the convergent validity of the factors. Discriminant validity is achieved if each item loads higher on its associated factor than on any other factor. As it is shown in Table 2, the condition for discriminant validity is also satisfied.

\subsection{Analytical Procedures}

To test the research hypotheses, data were analyzed using the logistic regression technique. Multiple regression analysis was not used because the dependent variable (EDI adoption) was dichotomous. Using a dichotomous variable in multiple regression analysis would necessarily violate the assumptions necessary for hypothesis testing. Also, logistic regression was chosen over discriminant analysis because the former technique requires fewer assumptions than the latter and, even when the assumptions required in discriminant analysis are satisfied, logistic regression still performs well.

In logistic regression, the model can be evaluated in the following three dimensions. The first cut is the assessment of the overall goodness-of-fit of the regression model. A nonsignificance in the goodness-of-fit chi-square statistic (i.e., $p>.05$ ) suggests that the model is not significantly different from a perfect model that correctly classifies all respondents into their respective groups.

Second, the model is evaluated on its overall classification accuracy by comparison with the accuracy of the chance model, which is determined by the formula $p^{2}+(1-p)^{2}$, where $p$ is the proportion of the sample in the first group. A significant $t$ value on the difference between the classification accuracy and chance accuracy indicates the superiority of the regression model over the chance model [33]. Finally, the Wald statistic was used to determine the significance of the regression coefficients of the hypothesized independent variables. 
Table 2

Results of Factor Analysis

\begin{tabular}{|c|c|c|c|c|c|c|c|}
\hline Item & BUS & PCO & $P I B$ & $P D B$ & SUP & $E X P$ & GOV \\
\hline PDB1 & & & & 0.80 & & & \\
\hline PDB2 & & & & 0.74 & & & \\
\hline PDB3 & & & & 0.83 & & & \\
\hline PDB4 & & & & 0.77 & & & \\
\hline PDB5 & & & & 0.79 & & & \\
\hline PDB6 & & & & 0.50 & & & \\
\hline PIB1 & & & 0.77 & & & & \\
\hline PIB2 & & & 0.82 & & & & \\
\hline PIB3 & & & 0.82 & & & & \\
\hline PIB4 & & & 0.86 & & & & \\
\hline PIB5 & & & 0.87 & & & & \\
\hline PCO1 & & 0.61 & & & & & \\
\hline $\mathrm{PCO} 2$ & & 0.75 & & & & & \\
\hline PCO3 & & 0.75 & & & & & \\
\hline PCO4 & & 0.71 & & & & & \\
\hline PCO5 & & 0.78 & & & & & \\
\hline PCO6 & & 0.76 & & & & & \\
\hline GOV1 & & & & & & & 0.68 \\
\hline GOV2 & & & & & & & 0.85 \\
\hline GOV3 & & & & & & & 0.79 \\
\hline BUS1 & 0.86 & & & & & & \\
\hline BUS2 & 0.88 & & & & & & \\
\hline BUS3 & 0.89 & & & & & & \\
\hline BUS4 & 0.89 & & & & & & \\
\hline EXP1 & & & & & & 0.76 & \\
\hline EXP2 & & & & & & 0.91 & \\
\hline EXP3 & & & & & & 0.86 & \\
\hline SUP1 & & & & & 0.90 & & \\
\hline SUP2 & & & & & 0.89 & & \\
\hline SUP3 & & & & & 0.84 & & \\
\hline Eigenvalue & 8.56 & 6.44 & 3.77 & 2.30 & 2.13 & 1.93 & 1.27 \\
\hline$\%$ of Variance & 23.13 & 17.40 & 10.18 & 6.21 & 5.76 & 5.21 & 3.43 \\
\hline
\end{tabular}

Note. Only loadings $\geq 0.50$ are shown. BUS = business partners' influence; $\mathrm{PCO}=$ perceived costs; $\mathrm{PIB}$ = perceived indirect benefits; $\mathrm{PDB}=$ perceived direct benefits; $\mathrm{SUP}=$ perceived support from the vendor; $\mathrm{EXP}$ = prior EDI experience; GOV = government influence; $\mathrm{EDI}=$ electronic data interchange.

\section{RESULTS}

The results of the logistic regression are shown in Table 3. As discussed previously, the model was assessed by three measures: goodness-of-fit, classification accuracy, and significance of individual regression coefficients.

The goodness-of-fit chi-square statistic is 616.80, with a significance level at $52.88 \%$, indicating that the model is not significantly different from a perfect model. The overall classification accuracy of the model is $76.4 \%$. Given that $38.4 \%$ or 241 respondents in our sample are adopters, the chance accuracy is $52.7 \%$. A $t$ test on the difference between these two levels of accuracy indicates that the logistic regression model performed significantly better than that of random choice. 
Table 3

Results of the Logistic Regression

\begin{tabular}{lccc}
\hline Factor & Coefficient & Wald Statistic & $p$ Value \\
\hline Perceived direct benefits & 0.3302 & 9.3299 & .0023 \\
Perceived indirect benefits & 0.0058 & 0.0034 & .9535 \\
Government influence & 0.1281 & 3.4123 & .0647 \\
Business partners influence & -0.6227 & 62.2022 & .0000 \\
Prior EDI experience & 0.7861 & 75.3485 & .0000 \\
Perceived support from the vendor & 0.3469 & 17.0251 & .0000 \\
Perceived costs & -0.2384 & 7.3659 & .0066 \\
\hline
\end{tabular}

Note. $-2 \log$ likelihood, $\chi^{2}(620, N=627)=607.832, p=.6289$. Goodness of fit, $\chi^{2}(620, N=627)=$ $616.795, p=.5288$. Adopters $n=241(38.4 \%)$; nonadopters $n=386(61.6 \%)$; total $N=627$; correctly classified adopters, $63.5 \%$; Correctly classified nonadopters, $84.5 \%$; correctly classified overall, $76.4 \%$; chance accuracy, $52.7 \% ; t$ value $=11.90 . \mathrm{EDI}=$ electronic data interchange.

With the previous two positive results, the significance of the regression coefficients of the hypothesized independent variables was examined to determine support for the hypotheses. As shown in Table 3, the coefficients of five variables were found to be strongly significantly different from zero $(p<.01)$. These five variables include perceived direct benefits, business partner influence, prior EDI experience, perceived support from the vendor, and perceived costs. The coefficients of perceived indirect benefits and government influence were not significant. Therefore, strong support was found for Hypotheses 1, 4, 5, 6, and 7. In other words, the EDI adoption decision of a small business is positively influenced by its level of perceived direct benefits, prior EDI experience, and the perceived level of support from the vendor, and negatively influenced by its level of perceived costs and the degree of influence from business partners. Neither the level of perceived indirect benefits nor the extent of government influence is a significant factor in the adoption decision of EDI in a small business.

\section{DISCUSSION}

\subsection{Technological Context}

Relative advantage (or perceived benefits in Iacovou et al.'s [21] terminology) has always been found to be significant in influencing IT adoption decisions. Following Iacovou et al. [21], this study distinguished direct from indirect benefits. The results show that perceived direct benefits have a significant influence on the EDI adoption decision, whereas perceived indirect benefits do not. There are two possible explanations for these findings. The first rests in the nature or characteristics of small businesses in IT acquisition and use. Small businesses in the manufacturing and trading industries, to which the respondents in this study belong, are in general more product oriented than customer oriented. Those indirect benefits such as enhancing competitive advantage and strengthening customer relations are less important than benefits that are directly related to day-to-day operation efficiency of the organization. This concurs with the findings by MacGregor et al.'s [2] survey on 
general IT acquisition by small businesses. In their study, more than half of the small firms in the study considered working faster and better within the organization as their major criterion for IT acquisition. Less than one sixth of them considered strengthening customer and interorganizational relations and improving market share as major criteria.

Another possible explanation is based on the fact that the EDI service being investigated in this study is of a business-to-government type. Those indirect benefits such as strengthening customer and business partner relationship might not be as prominent as in other business-to-business EDI services. In fact, a lot of the promotion activities that have been carried out by the particular EDI service provider in this study have been focused on more direct or operational benefits such as saving costs and time and improving the accuracy of data entry.

This finding suggests that small businesses tend to have an unbalanced treatment between direct and indirect benefits. When calculating the benefits, small firms focus more on immediate, direct effects than on long-term, indirect effects.

\subsection{External Environment Context}

Our study found a strong negative relation between influence from business partners and EDI adoption. In other words, compared to EDI nonadopters, those small businesses that adopted EDI considered the request and/or recommendations made by their business partners significantly less important. This finding seems to be inconsistent with prior studies that show that in small businesses, owing to their lack of financial resources and internal IT expertise, decisions are made through reliance on business partners and/or other firms in the industry. A plausible explanation for this finding is that when small businesses decided to adopt this technology, there were not many counterparts in the industry that were using it. As a result, the adoption decision of these early adopters might have been made without regard to others but with regard to costs and benefits instead. Another explanation is that, as there were very few firms using the technology, these firms did not experience pressure to meet industry standards [34] nor to conform to peer companies [16]. Nonadopters, on the other hand, might get more information and thus influence from other firms in the industry as the trend of using EDI develops. Nevertheless, they might still like to defer the adoption as long as possible because on one hand, it might remain unclear to them that their firm would receive any of the surplus [35], and, on the other hand, they might believe that the technology would result in an overall weaker bargaining position with their business partners and therefore lower profits [36].

This study did not find a significant relationship between influence from government and the likelihood to adopt EDI in small businesses. One plausible explanation is that as the government has already introduced mandatory measures for the migration from paper-based trade declarations to electronic submissions, the government influence may virtually become a default and be fully absorbed into the adoption decision-making process. This finding, together with that on business partners influence on the EDI adoption, suggest the view that small businesses tend to pay less attention to the activities regarding EDI by the government but 
rather more attention to what their counterparts in the industry say about the technology. In this case, the government may need to revise their promotion strategies accordingly.

\subsection{Organizational Context}

Prior EDI experience was found to be a significant determinant of EDI adoption by small businesses. This concurs with the findings by Banerjee and Golhar [34] on the importance of the EDI experience in making the adoption decision. The findings also support the notion by McGowan and Madey [18] of the importance of EDI knowledge in EDI adoption and implementation. Regardless of the size of an organization, one critical factor in the adoption decision of an IT is the extent of experience and/or knowledge of that particular type of technology as perceived by that organization.

The study also found a positive relation between EDI adoption by small businesses and their perceived level of support from the vendor. Compared to nonadopters, small business EDI adopters, at the time when they decided to adopt the technology, had a significantly more positive perception of the level of support by the vendor. This finding is consistent with findings in both Thong et al. [20] and Igbaria et al. [28]. Because small businesses generally lack resources to employ internal IT specialists, the availability and quality of external technical support thus could become very important in their adoption decision.

This finding, together with the preceding on prior EDI experience, suggests the importance of both EDI experience/knowledge and external support in the EDI adoption decision in small businesses. To help a small business decide to adopt EDI, two critical tasks have to be performed properly. First, the firm has to perceive itself as having a certain level of experience/knowledge of EDI. Second, the firm has to believe that it would get fairly good support from the vendor. Owing to their lack of internal IT expertise, small businesses tend to rely on external IS expertise for effective IS implementation [20].

Perceived costs were found to be a negative and significant factor on the EDI adoption decision in small businesses. Although the setup costs might not be very high when including subsequent implementation costs and other ongoing expenses during usage, the financial expenses to be incurred might still be an obstacle. Moreover, as adopting EDI usually impacts the administrative core of the business and additional or modified work procedures may be needed to be carried out, these required changes could be another obstacle to the adoption of EDI in small businesses.

\section{LIMITATIONS}

This study has several limitations. First, single responses from each small business were collected, thus leading to the possibility of response bias. The decision of using a single, key informant in the study was based on two considerations: (a) Unlike large organizations, decision making in small businesses is mostly done by a single 
person (i.e., owner/manager) and not a group of senior management, and (b) the names of the key informants were obtained from the provider of the EDI service being studied and thus were fairly accurate and up-to-date. Although the possibility of self-justifying reports still remains, the problem was deemed to be not a serious one given the unique characteristics of small business in terms of its top management structure.

The EDI service examined in this study was a business-to-government type of EDI service. Findings of prior studies on the role of power and trust between firms on the adoption and use of EDI (i.e., Hart \& Saunders [26]) may therefore be difficult to compare with our findings, and vice versa. In other words, interpretation of the findings should be made with care when extending it to those EDI services and products of a business-to-business nature. Also, the business-to-government nature of the EDI service being studied here precluded us from looking at the influence of competitors on EDI adoption in small businesses.

The adopter firms in this study were asked to respond to the items in the questionnaire based on their views at the time they decided to adopt the technology. This inevitably introduced some recall bias. To minimize this bias, only those firms that had subscribed to the EDI service for less than 1 year were included in the sample. However, the trade-off of doing so is that it might introduce another kind of bias or error. Firms that have subscribed to the service longer than 1 year (i.e., those "older" adopters), might be different from their younger counterparts in their views on the factors investigated in this study. Care should be taken in generalizing the findings of the study.

Finally, this study does not include variables such as management style and culture in the research model. Although it was originally understood that including intraorganizational and cultural factors might have enriched the content of the model, it might also have confounded the data analysis and the interpretation of the findings. Furthermore, to assess the impacts of those factors requires detailed analysis of the structure of an organization and in-depth, on-site studies. A cross-sectional survey methodology as used in this study may not be the most appropriate means to address these issues.

\section{IMPLICATIONS TO THE ADOPTION OF WEB-BASED EDI SYSTEMS}

This study also sheds light on Web-based EDI systems. The ValuNet software that we studied in this article was launched in 1997, a time when EDI was primarily built on private VANs. However, recent developments in Internet technology have advocated the feasibility of new Internet-based, or more specifically, Web-based EDI systems. As indicated by many practitioners, the difference between traditional EDI and Web-based EDI lies mainly on cost and connectivity [37-40]. Traditional EDI systems like the ValuNet function on privately owned VANs, where the transacting parties must subscribe to a designated VAN carrier. The proprietary nature of the network often leads to escalated overhead and operating costs. Besides, it also limits the transaction potential of EDI because different companies must adhere to the same standard to communicate with each other. Web-based EDI, on the other hand, offers far higher connectivity and much lower setup and operating costs because of 
the "openness" of the underlying network. This has profound implications to small businesses because one of our key findings is that cost is a major impedance barring small businesses from adopting EDI. In fact, the emergence of Web-based EDI offers new insights and implications toward the overall research model reported in this article. We discuss these in the following paragraphs.

\subsection{Characteristics of the EDI Innovation}

The results of this study show that perceived direct benefits (in the sense of operational gains) have a significant and positive impact on EDI adoption in small businesses. In the world of Internet, it is expected that such a relationship will persist because new Internet developments, like Java applets and XML, can almost fully replicate what used to be done on proprietary EDI networks [40,41]. In addition, because the Internet is built on common standards and interfaces, substantial effort in terms of product utilization and training can be eased if one adopts Web-based EDI systems. Many office and clerical users are already familiar with Web browsers and email systems, which implies possibly higher operation efficiencies on the Web.

What is more important here, however, is that perceived indirect benefits (that is, strategic or competitive advantages) may become important if one considers the adoption of Web-based EDI systems. A Web-based EDI system makes integration with existing IT structures easier and more manageable because both of them share common interfaces and operating platforms. For instance, within organization regime, a Web-based EDI system can easily share data and interface with preexisting company databases that are Web enabled. Similarly, data passing through a Web-based EDI can be updated on a timely basis on company Web sites to reflect up-to-date operational information. Externally, the ubiquity of the Internet and the universal connection standard enable companies to communicate with more trading partners without heavy network and software investments. This is particularly important for small businesses that lack financial and technical resources. Such internal and external integration, as argued by Iacovou et al. [21], is closely linked to possible indirect benefits such as improved customer services and business partner relations as well as organization image. Therefore, although perceived indirect benefits are not significant in this study, they should be taken into consideration in future Web-based EDI research in small businesses.

\subsection{External Influence}

The aim of EDI is to facilitate interorganizational exchange of documents or standardized information. As such, the influence of the "transacting bodies" (i.e., external parties such as business partners or sometimes governments) deserves special attention. Although this study shows that business partners may have negative influence on EDI adoption, such results may not be readily substantiated in the Internet environment. Specifically, because Web-based EDI systems involve relatively low operating and setup costs, the pressure from collaborating business partners may exert higher than usual influence on the adoption decisions of small busi- 
nesses. In other words, an interaction due to cost and external influence may well exist and could possibly lead to different outcomes when one considers Internet-based EDI systems. A well-articulated research program that involves multiple traditional and Web-based EDI systems may help uncover such influence structure in small businesses.

The influence of government is context specific because it largely depends on the nature of the EDI system under investigation. In this study, the ValuNet is part of government's initiative toward EDI transaction, yet government influence was found to be insignificant toward the adoption decisions of small businesses. This result provides counterevidence as opposed to Neo et al. [15], and it undermines the role of government in small business EDI-related studies. One could hardly expect such a factor to behave differently in the Internet environment because the nature of transaction is not altered across media.

\subsection{Organizational Readiness}

Organizational readiness primarily concerns the technical and financial sophistication of the organization. As suggested earlier, the Internet can substantially bring down the cost of adopting and implementing EDI. Subscribing to Internet services is often much cheaper than subscribing to private VANs, whereas the latter typically involves heavy software expenses, maintenance costs, monthly service fees, and charges per transaction. Taken together, these cost components can easily add up to a total expense that is 10 times higher than the cost of Web-based EDI [37]. Furthermore, as Internet increasingly becomes part of overall IT architectures in many organizations, the incremental cost of adopting Web-based EDI systems tends to be lower, especially when it is weighed against the potential benefit of being able to perform online and real-time transactions with more trading partners. This may undermine the importance of cost in Web-based EDI adoption. Therefore, one could expect the perceived cost dimension to be of much less significance in Web-based EDI adoption in small businesses.

Similarly, because the Internet is increasingly accepted by business users and its user population is growing at unprecedented rate, the vendor support factor that is important in traditional EDI systems may play a less significant role in Web-based EDI adoption. Due to the well-known interfaces of Web browsers and the highly standardized transmission protocols like FTP, SMTP, and HTML, many office users are already familiar with Web applications and their user interfaces. This may lessen the role of EDI vendors in terms of customer training during initial software setup and product support during subsequent transactions. Hence, perceived vendor support may become relatively minor in Web-based EDI adoption.

Finally, comparing to the other two readiness variables (i.e., perceived costs and perceived support from the vendor), prior EDI experience is a relatively persistent factor because it focuses on understanding EDI operations and the experience of dealing with EDI systems. EDI is a unique concept that aims at automating routine transactions such as purchase orders, invoices, or shipment notices. For organizations that do not have prior exposure to EDI software, they may need to invest additional time, effort, or sometimes even money just to understand the underlying principle of EDI transactions and to get acquainted with its operations. Therefore, 
having prior knowledge or exposure on EDI may reduce the uncertainty faced by small businesses and facilitate their adoptions of EDI systems. Because EDI knowledge is invariable across network platforms, such gain due to prior experience may well carry over to the Internet platform. In other words, regardless of traditional or Web-based EDI systems, prior experience should continue to play an important role in small business adoption decisions.

To conclude, technology is changing in a very fast pace and new developments, such as Web-based EDI systems, may continue to evolve, which leads to improved business operations. In face of rapid technological change, the small business adoption model studied in this article is subject to future modifications or calibrations. In the case of Web-based EDI, we posit that direct and indirect benefits, external influence, and prior EDI experience may continue to play important roles in future adoption studies. Government influence is context specific and it might not be relevant for certain EDI systems, and perceived cost and vendor support may no longer be important determinants for Web-based EDI adoptions.

\section{CONCLUSIONS}

Because electronic commerce or electronic business is increasingly the focus of many business and IT conferences, and EDI is one of the key applications in the electronic commerce arena, the need to understand more about what factors are important in the adoption decision of an organization is unquestionable. This study addressed the EDI adoption issue in the context of small businesses by testing an EDI adoption model for small businesses. The model was empirically examined via data collection from 627 small businesses, with $38 \%$ of them having adopted the technology. The findings have a number of implications on research and practice.

\subsection{Implications for Research}

As pointed out in the introduction of this article, research on EDI adoption, particularly in the context of small businesses, is rare although needed. This study addressed the issue by integrating the EDI adoption model developed by Iacovou et al. [21] with findings in other related studies. The integrated model was found to be of value. The results indicate that like other IT adoption, decisions to adopt EDI are not primarily based on the characteristics of the technology itself but are also dependent on other factors related to the internal organizational readiness and the external environment, including internal prior EDI experience, perceived level of support from the vendor, influence from business partners, and perceived costs to be incurred. Future work is needed, however, to reexamine the proposed model in other EDI adoption settings, particularly in a business-to-business EDI context or in other IT innovations. As indicated by Dennis et al. [42], it is necessary to test a research model in different contexts. By doing so, additional knowledge on the issue may be gathered.

The finding of a negative relationship between the importance of industry influence and small business EDI adoption is both interesting and thought provoking. The rationale we have provided for this unexpected result is that because the adoption and/or diffusion of EDI in the small business sector was still at the early stage 
with very few firms using it, there was just not enough critical mass to make this factor influential. This suggests an interesting and possibly fruitful line of research that investigates the validity of the theoretical model and the significance of the factors involved along the "life cycle" of the diffusion of the technology. A longitudinal study that examines the model at different stages of the diffusion of the technology is recommended.

The focus of this study was on adoption of EDI, which should be considered as part of a broader issue of management of technology. As adopting a technology should eventually lead to some form of positive impacts or advantages-which can be operational, managerial, and strategic in nature for an organization-evaluation and assessment of the adoption and implementation of the technology are important also. Added work should therefore be done to extend the model examined in this study to include integration and impact, as suggested in Iacovou et al. [21].

Last, EDI is a kind of technology that is sitting between old technologies using ANSI X12 or EDIFACT standards and new Internet-based XML or open EDI platforms. It has been estimated that although VANs carried about $95 \%$ of all EDI volume in 1997, half of the volume might be moved to the Internet-based platform by 2002 [43]. It therefore would be interesting to investigate how firms, both large and small, move from using an old technology to a new technology, which basically provides the same services, from a technology adoption perspective.

\subsection{Implications for Practice}

From a managerial point of view, the findings of this study suggest that, in the eyes of small businesses, EDI still is not considered as something that enables them to gain major strategic benefits or competitive advantages. Immediate and direct benefits are more important for them in deciding to adopt the technology. Although these benefits are exactly what the vendor has been emphasizing in their promotion activities, EDI initiators-including EDI vendors, service providers, or government authorities - should also think about their underlying rationale of introducing and promoting the technology to small businesses in the long run. EDI is the kind of IT that is developed and designed for enhancing the efficiency and effectiveness of business operations at not just the operational but also the managerial and strategic levels. If properly integrated into organizational use of other information technologies, it can be of significant strategic value to the organization [44].

The unbalanced treatment between direct and indirect benefits of EDI among small businesses also indicates that they seem to possess a reactive attitude in adopting the technology and focus more on managing the present than preparing for the future, a phenomenon that is uncommon in adoption of complex information technologies [27]. This may also suggest the intensive pressure experienced by these small businesses and/or the myopia of their IT strategies, which may again be due to two well-known reasons: (a) lack of financial resources and technical expertise and (b) failure to perceive the net benefits that the technology can offer. Therefore, heavy subsidization and/or incentive schemes, in terms of providing both financial and technical support by the EDI initiators, are recommended to help alleviate the problems and facilitate faster adoption, thus leading to a critical-mass effect [21]. 
Finally, a better knowledge of executive decisions about adoption of IT in small businesses should be helpful to their practicing managers in understanding the qualifying factors for which EDI is most appropriate to their organizations.

\section{REFERENCES}

[1] L. Bouchard, "Decision criteria in the adoption of EDI," Proc. 14th Annual Int. Conf. on IS, 1993, pp. 365-376.

[2] R. C. MacGregor, P. Waugh, D. J. Bunker, and J. F. Courtney, "Adoption of EDI by small business: Are the advocates in tune with the views of small business-A pilot study," Proc. 30th Annual Hawaii Int. Conf. on System Sciences, 1997, pp. 42-47.

[3] E. B. Swanson, "Information systems innovation among organizations," Management Science, vol. 40, no. 9, pp. 1069-1092, 1994.

[4] "Introduction," The U.S. Small Business Administration, (Oct. 15, 1999). http//www.sbaonline. sba.gov/intro.html, 1998.

[5] E. M. Rogers, Diffusion of Innovations, 3rd ed. New York: Free Press, 1983.

[6] G. C. Moore and I. Benbasat, "Development of an instrument to measure the perceptions of adopting and information technology innovation," Information Systems Research, vol. 2, no. 3, pp. 192-222, 1991.

[7] A. Rai and G. S. Howard, "Propagating CASE usage for software development: An empirical investigation of key organizational correlates," OMEGA, vol. 22, no. 2, pp. 133-147, 1994.

[8] G. Premkumar and M. Potter, "Adoption of computer aided software engineering (CASE) technology: An innovation adoption perspective," Database Advances, vol. 26, no. 2-3, pp. 105-123, 1995.

[9] L. G. Tornatzky and K. J. Klein, "Innovation characteristics and innovation adoption-implementation: A meta-analysis of findings," IEEE Trans. on Engineering Management, vol. 29, no. 1, pp. 28-45, 1982.

[10] J. C. Brancheau and J. C. Wetherbe, "The adoption of spreadsheet software: Testing innovation diffusion theory in the context of end-user computing," Information Systems Research, vol. 1, no. 2, pp. 115-143, 1990.

[11] R. G. Fichman, "Information technology diffusion: A review of empirical research," Proc. 13th Inter. Conf. on IS, 1992, pp. 195-206.

[12] M. B. Prescott and S. A. Conger, "Information technology innovations: A classification by IT locus of impact and research approach," Data Base, vol. 26, no. 2-3, pp. 20-41, 1995.

[13] R. O'Callaghan, P. J. Kaufmann, and B. R. Konsynski, "Adoption correlates and share effects of electronic data interchange systems in marketing channels," Journal of Marketing, vol. 56, no. 2, pp. 45-56, 1992.

[14] G. Premkumar, K. Ramamurthy, and S. Nilakanta, "Implementation of electronic data interchange: An innovation diffusion perspective," Journal of Management Information Systems, vol. 11, no. 2, pp.157-186, 1994.

[15] B. S. Neo, P. E. Khoo, and S. Ang, "The adoption of TradeNet by the trading community: An empirical analysis," Proc. 15th Annual Inter. Conf. on IS, 1994, pp.159-174.

[16] G. Premkumar and K. Ramamurthy, "The role of interorganizational and organizational factors on the decision mode for adoption of interorganizational systems," Decision Sciences, vol. 26, no. 3, pp. 303-336, 1995.

[17] D. H. Drury and A. Farhoomand, "Innovation adoption of EDI," Information Resources Management Journal, vol. 9, no. 3, pp. 5-13, 1996.

[18] M. K. McGowan and G. R. Madey, "The influence of organization structure and organizational learning factors on the extent of EDI implementation in U.S. firms," Information Resources Management Journal, vol. 11, no. 3, pp.17-27, 1998.

[19] L. Raymond and R. Bergeron, "EDI success in small and medium-sized enterprises: A field study," Journal of Organizational Computing and Electronic Commerce, vol. 6, no. 2, pp. 161-172, 1996.

[20] J. Y. L. Thong, C.S. Yap, and K. S. Raman, "Top management support, external expertise and information systems implementation in small businesses," Information Systems Research, vol. 7, no. 2, pp. 248-267, 1996. 
[21] C. L. Iacovou, I. Benbasat, and A. S. Dexter, "Electronic data interchange and small organizations: Adoption and impact of technology," MIS Quarterly, vol. 19, no. 4, pp. 465-485, 1995.

[22] F. Bergeron and L. Raymond, "The advantages of electronic data interchange," Data Base, vol. 23, no. 4, pp. 19-31, 1992.

[23] T.H. Kwon and R. W. Zmud, "Unifying the fragmented models of information systems implementation," in Critical Issues in Information Systems Research, J. R. Boland and R. Hirschheim, Eds. New York: Wiley, 1987, pp. 227-251.

[24] P. Cragg and M. King, "Small-firm computing: Motivators and inhibitors," MIS Quarterly, vol. 17, no. 1 , pp. 47-60, 1993.

[25] H. K. C. Pfeiffer, The Diffusion of Electronics Data Interchange. New York: Springer-Verlag, 1992.

[26] P. Hart and C. Saunders, "Power and trust: Critical factors in the adoption and use of electronic data interchange," Organization Science, vol. 8, no. 1, pp. 23-42, 1997.

[27] P. Y. K. Chau and K. Y. Tam, "Factors affecting the adoption of open aystems: An exploratory study," MIS Quarterly, vol. 21, no. 1, pp. 1-21, 1997.

[28] M. Igbaria, N. Zinatelli, P. Cragg, and A. L. M. Cavaye, "Personal computing acceptance factors in small firms: A structural equation model," MIS Quarterly, vol. 21, no. 3, pp. 279-305, 1997.

[29] C. S. Yap, J. Y. L. Thong, and K. S. Raman, "Effect of government incentive on computerisation in small business," European Journal of Information Systems, vol. 3, no. 3, pp. 191-206, 1994.

[30] M. R. Hoogeweegen, R. J. Streng, and R. W. Wagenaar, "A comprehensive approach to assess the value of EDI," Information \& Management, vol. 34, no. 3, pp. 117-127, 1998.

[31] V. Arunachalam, "Electronic data interchange: Issues in adoption and management," Information Resources Management Journal, vol. 10, no. 2, pp. 22-31, 1997.

[32] J. C. Nunnally, Psychometric Theory, 2nd ed. New York: McGraw-Hill, 1978.

[33] J. F. Hair, R. E. Anderson, R. L. Tatham, and W. C. Black, Multivariate Data Analysis With Readings, 4th ed. Englewood Cliffs, NJ: Prentice-Hall, 1995.

[34] S. Banerjee and D. Y. Golhar, "Electronic data interchange: Characteristics of users and nonusers," Information \& Management, vol. 26, no. 1, pp. 65-74, 1994.

[35] E. K. Clemons and M. Row, "Limits to interfirm coordination through information technology: Results of a field study in consumer goods distribution," Journal of Management Information Systems, vol. 10, no. 1, pp.73-95, 1993.

[36] F. J. Riggins and T. Mukhopadhyay, "Interdependent benefits from interorganizational systems: Opportunities for business partner reenginneering," Journal of Management Information Systems, vol. 11, no. 2, pp. 37-58, 1994.

[37] C. Wilde, "New life for EDI?," InformationWeek, vol. 622, pp. 65-67, Mar. 1997.

[38] L. Greenemeier, "EDI-INT opens e-business avenues," Midrange Systems, vol. 11, no. 12, p. 34, 1998.

[39] C. Sullivan, "Beyond traditional EDI: Electronic commerce demystified," Inform, vol. 12, no. 10, pp. 22-25, 1998.

[40] T. Werner, "EDI meets the Internet," Transportation and Distribution, vol. 40, no. 6, pp. 36-44, 1999.

[41] D. Allen, "New directions for EDI," Telecommunications, vol. 32, no. 11, p. 63, 1998.

[42] A. R. Dennis, J. R. Nunamaker, and D. R. Vogel, "A comparison of laboratory and field research in the study of electronic meeting systems," Journal of Management Information Systems, vol. 7, no. 3, pp. 107-135, 1990-1991.

[43] T. Wilson, "EDI is alive and kicking, study says," InternetWeek, issue 801, p.15, Feb. 21, 2000.

[44] P. M. C. Swatman and P. A. Swatman, "EDI system integration: A definition and literature survey," Information Society, vol. 8, no. 3, pp. 169-205, 1992. 
APPENDIX

Items Used in This Study

\begin{tabular}{|c|c|}
\hline Variable/Item & Description \\
\hline \multicolumn{2}{|l|}{ PDB } \\
\hline PDB1 & Improve data accuracy \\
\hline PDB2 & Improve security of data \\
\hline PDB3 & Improve operation efficiency \\
\hline PDB4 & Speed up application process \\
\hline PDB5 & Reduce clerical errors \\
\hline PDB6 & Reduce operations costs \\
\hline \multicolumn{2}{|l|}{ PIB } \\
\hline PIB1 & Improve organization image \\
\hline PIB2 & Improve competitive advantage \\
\hline PIB3 & Benefit other business practices \\
\hline PIB4 & Improve customer services \\
\hline PIB5 & Improve relationship with business partners \\
\hline \multicolumn{2}{|r|}{1} \\
\hline GOV1 & Promotion by government departments \\
\hline GOV2 & Progress mandatory measures introduced by the government \\
\hline GOV3 & Closing of paper-receipt counters by 31 March 2000 \\
\hline \multicolumn{2}{|l|}{ BUS } \\
\hline BUS1 & Requested by important business partners \\
\hline BUS2 & Requested by majority of business partners \\
\hline BUS3 & Recommended by important business partners \\
\hline BUS4 & Recommended by majority of business partners \\
\hline \multicolumn{2}{|r|}{ 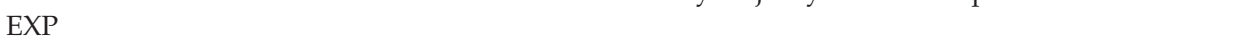 } \\
\hline EXP1 & End users' experience on using ValuNet \\
\hline EXP2 & End users' experience on using other EDI software packages \\
\hline EXP3 & End users' understanding on ValuNet \\
\hline \multicolumn{2}{|l|}{ SUP } \\
\hline SUP1 & Technical support provided by the vendor \\
\hline SUP2 & Customer hotlines provided by the vendor \\
\hline SUP3 & Training courses provided by the vendor \\
\hline \multicolumn{2}{|l|}{$\mathrm{PCO}$} \\
\hline PCO1 & Long lead time to complete the registration process \\
\hline PCO2 & Long lead time to install the EDI package \\
\hline PCO3 & Long lead time to complete the training before starting to use \\
\hline $\mathrm{PCO} 4$ & High setup costs \\
\hline PCO5 & High running costs \\
\hline PCO6 & High training costs \\
\hline
\end{tabular}

Note. $\mathrm{PDB}=$ perceived direct benefits; $\mathrm{PIB}=$ perceived indirect benefits; GOV = government influence; BUS = business partners' influence; EXP = prior EDI experience; SUP = perceived support from the vendor; $\mathrm{PCO}=$ perceived costs. 